\section{EMBRYRIDDLE \\ Aeronautical University}

SCHOLARLY COMMONS
International Journal of Aviation, Aeronautics, and Aerospace

$6-24-2017$

\title{
Simulation Challenges - Student Perception of Air Traffic Control Simulation
}

\author{
William Coyne \\ Embry-Riddle Aeronautical University - Daytona Beach, coynea7e@erau.edu \\ Stephen C. Rice \\ Embry-Riddle Aeronautical University, rices15@erau.edu \\ Scott Winter \\ Embry-Riddle Aeronautical University, scott.winter@mac.com \\ Gajapriya Tamilselvan \\ Florida Institute of Technology - Melbourne, gtamilselvan2014@my.fit.edu \\ Paul V. Drechsel \\ University of North Dakota, drechsel@aero.und.edu
}

Follow this and additional works at: https://commons.erau.edu/ijaaa

Part of the Curriculum and Instruction Commons

\section{Scholarly Commons Citation}

Coyne, W., Rice, S. C., Winter, S., Tamilselvan, G., \& Drechsel, P. V. (2017). Simulation Challenges - Student Perception of Air Traffic Control Simulation. International Journal of Aviation, Aeronautics, and Aerospace, 4(3). https://doi.org/10.15394/ijaaa.2017.1088

This Article is brought to you for free and open access by the Journals at Scholarly Commons. It has been accepted for inclusion in International Journal of Aviation, Aeronautics, and Aerospace by an authorized administrator of Scholarly Commons. For more information, please contact commons@erau.edu. 
Buzzwords such as NextGen (Next Generation Air Transportation System) and SESAR (Single European Sky ATM Research) elicit a sense of excitement or trepidation as to what this means for the world of Air Traffic Management (ATM). Some collegiate institutions, including members of the University Aviation Association (UAA), have degree programs that include air traffic control curriculum. The directions from the FAA in the Behavioral Objectives/Academic Standards (2006) required institutions to develop their curriculum and

While the behavioral objectives are intended to be knowledge and comprehension levels of learning (e.g., identify the purpose of a clearance), it is highly recommended that the student be provided instructional activities in which they go beyond rote

learning and memorization. It is recommended that instructional activities that require application of this knowledge to various example aviation or air traffic situations be included as well. (p. 4)

Therefore, several of the institutions exceeded the basic requirements and included high-fidelity simulation in their programs. The technological advancements with NextGen indicate that controllers will be required to use automation more than ever. A number of tasks that were done manually before will now be handled by automation, and more decisions that a controller makes to separate aircraft will be assisted by new technologies.

The purpose of this paper will be to evaluate the student's perception on the use of high-fidelity simulation as it is currently employed in the curriculum. Therefore, this study will examine input from several of the FAA authorized Air Traffic Collegiate Training Initiative (AT-CTI) programs.

The task for ATM faculty and researchers is to determine what benefit highfidelity simulation can provide in this new environment. Areas such as problemsolving, teamwork, repetition, situational awareness examples, coordination, cooperation, decision making, and communication can all be evaluated and improved with the use of high-fidelity simulation. The goal with the introduction of new ATM technologies is to use simulation to improve the student's capability to succeed and lessen the time necessary for training. In Treiber's (1994) seminal case study at the Minnesota Air Traffic Control Training Center, a quote from an active air traffic control (ATC) manager said that "the design for air traffic control training would be $90 \%$ simulation and $10 \%$ would occur on-the-job. The more simulation you have, the better-trained folks you'll have" (p. 22). Even though 
NextGen technologies are the future, this study relates the importance of simulation has been instrumental in training for decades.

The aviation industry has faced incredible challenges over the last few years, such as the "merger fever" of the airline industry, the emphasis on aviation and commercial safety, sequestration and budget issues, and the future of the space industry. The importance of the aviation industry cannot be overstated; it is a powerful force within the U.S. economy. In a Department of Transportation report from November 2016, data provided indicates that the industry contributed $\$ 1.6$ trillion in total economic activity, which is $5 \%$ of the U.S. Gross Domestic Product (GDP). In that same timeframe, over 11 million workers were employed in different jobs in the aviation industry with $\$ 447$ billion in earnings (Federal Aviation Administration [FAA], 2016a). The report states that "As the U.S. economy continues to improve in spite of recent global economic uncertainty and unrest, other U.S. industries and consumers depend on civil aviation's ability to provide reliable value-added services that facilitate business and personal opportunities" (p. 4). An integral part of the aviation industry is the air traffic controller. In the U.S., there are

More than 14,000 federal air traffic controllers in airport traffic control towers, terminal radar approach control facilities and air route traffic control centers guide pilots through the system. An additional 1,292 civilian contract controllers and more than 10,000 military controllers also provide air traffic services for the NAS (FAA, 2016b, p. 10)

As the FAA moves toward implementation of the NextGen system, training the air traffic controller workforce will become crucial if the FAA is to be successful.

\section{Review of Literature}

\section{Air Traffic Control Training History}

The AT-CTI program has been one of the training processes utilized by the FAA for over 20 years to meet their hiring needs for air traffic controllers. In 1989, the FAA established a program with colleges and universities to provide initial training on air traffic control basics. Before the establishment of the AT-CTI program, two studies (Means et al., 1988; Northern NEF, Inc., 1988) were commissioned by the FAA to review air traffic control training procedures. These studies provided recommendations that established the basis for collegiate ATC training. 
The AT-CTI program began with two institutions in 1989; three more were added in 1991 and eventually grew to a core of 14 institutions. By 2011 there was a total of thirty-six institutions in the AT-CTI program. In February 2014, the FAA initiated a change in the hiring process for air traffic controllers. Instead of three hiring streams, which included veterans/military, AT-CTI, and the general public they went to two. The Collegiate Training Initiative (CTI) applicants were now included in a public at large announcement (FAA, 2013). The initial requirements for an air traffic control specialist has not changed: be a U.S. citizen, pass a medical examination, pass a security investigation, have three years of progressively responsible work experience, or a bachelor's degree, or a combination of postsecondary education and work experience that total three years, pass a FAA air traffic pre-employment test and speak English clearly (FAA, 2016c).

The primary purpose of the AT-CTI program was to "provide the FAA with qualified applicants possessing a broad-based knowledge of the aviation industry to fill ATC positions" (Work, 2007, p. 1). The institutions in the program today include both two and four-year colleges and universities which offer associate, bachelor, and master's degrees. The education provided by the schools offer several advantages to the FAA: The institutions produce candidates with college degrees, a broad-based knowledge of the aviation industry, and a basic level of training in ATC. Ruiz and Ruiz (2003) conducted an extensive literature review identifying several objectives of the AT-CTI program: (a) to test the concept that nonfederal, postsecondary educational institutions can develop, deliver, and implement ATC recruiting, selection and training programs; (b) to attract females and minorities to careers in ATC; (c) to develop a more educated workforce in the FAA; and (d) to use collegiate aviation as one of the primary means of meeting the future needs of the FAA for ATC specialists.

The partnership developed between higher education institutions and the FAA required that schools provide students who completed an aviation-related degree and that the curriculum meets the Air Traffic Basics course teaching objectives (FAA, 2010a). The curriculum covers such topics as airports, fundamentals of radar, FAA orders and manuals, airspace, basic navigation, and wake turbulence. Institutions were required to develop their curriculum and encouraged to do it in creative and instructive ways. It is also highly recommended that students be provided instructional activities in which they go beyond rote learning and memorization (FAA, 2006). Therefore, experienced air traffic control faculty at a number of the CTI schools saw the need to utilize high-fidelity simulation in the curriculum and took steps to purchase simulation equipment from several different vendors. 


\section{Simulation in Air Traffic Control Training}

Research has shown that the use of simulation in ATC provides realistic environments and tasks. ATC has been referred to as a complex cognitive or highperformance job, especially as it relates to the learning process (Schneider, 1990; Van Merrienboer, 1997). According to Allermand and Rosenkvist (2011), simulation has the potential for opening up a learning universe which is unique. The simulator can build a bridge between the benign setting of the classroom and the complex reality in which the participants use their skills - even beyond the limit of their abilities - while at the same time offering a framework for reflection and training, which is necessary to learn from a situation. Blanken (2002) stated, "simulation is a means of reproducing a representation or real working conditions to enable learners to acquire and practice skills, knowledge, and attitudes" (p. 162). There are a number of benefits that simulation can provide if utilized properly in the training process: (a) it can shorten the time needed for on-the-job training (OJT), (b) the use of a personal computer for ATC training is more cost efficient, and (c) simulation in the training process provides replay capabilities that allow the student to concentrate on specific tasks (Blanken). Two areas that are essential in ATC training are problem solving and teamwork. The simulator is an excellent tool that can be used to train teamwork practices and also allows for the reinforcement of learned concepts. Simulation can be used as a means of enhancing air traffic control training and reducing the time to full certification. Fisher and Kulick (1998) indicate that training must provide "the knowledge and skills required to achieve and maintain successful job performance" (p. 273). Further, seminal work by Hopkin (1995) is in agreement and states that the:

Purpose of air traffic control training is to produce sufficient qualified controllers to meet staffing requirements, all of whom possess and can apply the requisite knowledge and skills to be safe and efficient and are motivated to remain as controllers. (p. 153)

When simulators are used to train air traffic controllers, it does not require that you have a certain density or actual air traffic situations. Using simulation allows instructors to create real-time traffic scenarios that provide a standard training format for students to develop the skills and experience that it would otherwise have to obtain through on-the-job training (OJT). Some simulators have the capability to display weather and create unusual situations which can be repeated on a consistent basis, instead of waiting for a situation to occur in the OJT environment. Simulators can also be used to validate new procedures, evaluate airspace changes, and to conduct recurring training. 
In the current training regimen, all initial hires attend air traffic control training at the FAA Academy before assignment to an air traffic control facility. The academy uses lecture as well as medium-fidelity and high-fidelity simulation. The curriculum taught at the academy is general to air traffic control practices and procedures throughout all types of facilities. As changes to ATC procedures and automation technology occur, the academy evaluates courses and makes adjustments as necessary. A goal of the FAA is to reduce the training times for terminal and enroute controllers. Data taken from the 2016-2025 FAA Controller Workforce Plan (FAA, 2016b), as shown in Table 1 indicates the FAA's goals and training time to certification at all facility levels.

Table 1

Years to Certify

\begin{tabular}{|c|c|c|c|c|c|c|c|}
\hline Facility & Facility & FAA & FY & FY & FY 2009 & FY 2010 & FY 2011 \\
\hline Type & Level & Goal & 2007 & 2008 & & & \\
\hline Terminal & $4-6$ & 1.5 & 1.88 & 2.13 & 2.47 & 2.27 & 1.81 \\
\hline Terminal & $7-9$ & 2.0 & 1.92 & 2.26 & 2.50 & 2.36 & 2.04 \\
\hline Terminal & $10-12$ & 2.5 & 2.04 & 2.30 & 2.59 & 2.33 & 2.16 \\
\hline Enroute & All & 3.0 & 2.57 & 2.75 & 3.01 & 3.02 & 3.00 \\
\hline
\end{tabular}

Note. More recent hiring classes (FY2012 forward) are not reported as there are still greater than 10 percent of the class in progress, resulting in continuously changing metrics as those students certify or fail.

Simulations are classified as high, medium, and low fidelity. In air traffic control, high-fidelity simulators are those that utilize very realistic materials and equipment that represent or mirror the actual task(s) performed in an air traffic control facility. Medium-fidelity simulators emulate most of the actual tasks conducted in an air traffic control facility. Low fidelity simulations use minimal representations and are much less realistic when compared to what is used on the job.

A cursory review of the institutional websites of all 36 AT-CTI schools indicates that a majority include some form of simulation in their academic programs. At least 60\% (22 of 36) of the programs have some form of simulation that covers tower, terminal radar, or enroute radar. One could surmise, and the review would indicate, that along with the FAA Academy simulation usage is an integral part of the air traffic control training regimen. 
A pioneering case study by Treiber (1994) at the Minnesota Air Traffic Control Training Center (MNATCTC), which used simulation extensively, assessed the applicability of virtual reality to academic and air traffic control training situations. The purpose of the study was to identify the social and psychological effects of simulation on collegiate ATC students. Before the MNATCTC opened, ATC training was said to take a "high tech, low touch approach" (p. 7). This essentially meant that controllers were using advanced technology to work air traffic, but the training was still using paper and pencil methods. The schedule of training at the center was total immersion; students were in lecture classes or laboratory sessions five days a week, eight hours a day over a six-month period. Treiber (1994) placed the students into five groups for the study. Two groups were in training at the time they were interviewed, and three groups were graduates who voluntarily participated. The responses from the student groups were that classroom instruction could not match what they were able to accomplish with simulation. The groups felt that they learned several things: (a) complex map analysis skills, (b) communication skills, and (c) memory skills that were essential for employment along with the critical teamwork skills they would need on a daily basis in an enroute center (Treiber, 1994).

\section{Future of Air Traffic Control Training}

The future of air traffic control lies in the FAA's NextGen Transportation system. In simple terms, this is a quantum leap from an environment that has used ground-based radar systems for separation to one that is satellite-based. In an article in Live Science, where the mysterious disappearance of Malaysia Airlines Flight 370 was discussed, Wall (2014) included a statement from the FAA about how the transformation to satellite-based technology might have prevented the disappearance by stating:

Satellite navigation will let pilots know the precise locations of other airplanes around them. That allows more planes in the sky while enhancing the safety of travel. Satellite landing procedures will let pilots arrive at airports more predictably and more efficiently. Moreover, once on the ground, satellite monitoring of airplanes leads to getting you to the gate faster. (New tracking system coming, para. 3)

To convert the system and ensure the flying public better understands the changes, the FAA is leveraging many of the existing forms of technology and relying on many partners such as universities to help in the process (FAA, 2010b). The changes with NextGen involve all aspects of flight, from before takeoff, after takeoff, enroute and over the ocean, and on approach to landing. Some key elements of the NextGen technologies consist of (FAA 2016d): 
1. Automatic dependent surveillance-broadcast (ADS-B) is the satellite-based successor to radar. ADS-B uses Global Positioning System (GPS) satellite signals to provide accurate aircraft information to the controller and provide information to aircraft properly equipped.

2. Collaborative Air Traffic Management Technologies (CATMT) is a suite of enhancements to the decision-support and data-sharing tools used by air traffic management personnel. These enhancements will enable a more collaborative environment among controllers and operators, improving efficiency in the National Airspace System.

3. Data Communications (Data Comm) will enable controllers to send digital instructions and clearances to pilots. Precise visual messages that appear on a cockpit display can interact with an aircraft's flight computer. Offering reduced opportunities for error, Data Comm will supplant voice communications as the primary means of communication between controllers and flight crews

4. National Airspace System Voice System (NVS) will supplant FAA's aging analog voice communication system with state-ofthe-art digital technology. NVS will standardize the voice communication infrastructure among FAA facilities, and provide greater flexibility to the air traffic control system.

5. NextGen Weather will help reduce weather impact by producing and delivering tailored aviation weather products via System-Wide Information Management (SWIM), helping controllers and operators develop reliable flight plans, make better decisions, and improve on-time performance. NextGen Weather is accomplished through collaboration between FAA, NOAA, and NASA.

6. SWIM is the network structure that will carry NextGen digital information. SWIM will enable cost-effective, real-time data exchange and share among users of the National Airspace System.

7. Terminal Flight Data Manager (TFDM). TDFM is a tool that will help better manage arrivals and departures, which allows controllers to use SWIM technology to share real-time data.

A majority of aviation accidents and incidents over the years have been due to the lack of poor communication (Patty, 2016; Baron, 2014). For example, analog voice communication between pilot and controller has been the primary method of relaying information. Two NextGen programs that provide a snapshot to some of the changes that controllers and pilots will experience in the future are Data Comm and SWIM. With NextGen, more data communication will be utilized, such as 
Controller Pilot Data Link Communications (CPDLC), which will reduce the chance of error, reduce workload and allow for voice communications to be used for more complex procedures. Another feature of NextGen is SWIM. System-Wide Information Management (SWIM) is a structured network that will allow users of the National Airspace System (NAS) to receive real-time data. In this collaborative environment, a number of partners are participating in one form or another. An example cited by the FAA is where "the Florida NextGen Test Bed (FTB) is a FAA initiative to develop a NextGen research and demonstration facility at the EmbryRiddle Aeronautical University adjacent to the Daytona Beach International Airport (DAB) in Florida. The FTB provides a platform for new NextGen demonstrations to be efficiently conducted at an early stage without affecting the National Airspace System (NAS)" (FAA, 2015, para. 1).

\section{Method}

A collaborative effort was initiated between air traffic management programs at several of the AT-CTI programs to evaluate the perception of students using high-fidelity simulation in the curriculum. Some collegiate institutions use simulators that emulate control tower, terminal radar and enroute radar and nonradar. There are a number of vendors that supply simulation hardware and software to the collegiate institutions across the country. As leaders at the AT-CTI institutions, the value of using simulations is recognized as an integral part of training in air traffic control.

Based on the subject matter expertise of faculty, a survey instrument was created to measure student feedback on their perception and the value of using highfidelity simulation. In the creation of any instrument, two qualities are imperative: validity and reliability. Gall, Gall, and Borg (2006) have indicated that the survey instrument has validity if it can measure what was learned, and reliability of the instrument if it can produce consistent results when used. After the survey questionnaire was completed, faculty from both institutions reviewed the questionnaire and through an iterative process provided comments and feedback. This process occurred through personal conversations, face-to-face meetings, and email. After all comments and feedback were reviewed, the questionnaire was finalized.

\section{Participants}

The participants in this study were volunteer students from University Aviation Association (UAA) members and several who were also FAA approved AT-CTI institutions. The selection of students was based on any that were currently 
in either of the air traffic academic programs at both schools. This included students who were pursuing air traffic management as a major or students that were pursuing majors in aeronautical science, airport management, or commercial aviation but were enrolled in the ATC minor.

Sample. A sample size of 86 was included in this study. The students were notified in the January-April 2017 timeframe and asked to voluntarily take the ATC survey questionnaire. The data that were obtained by the researchers came from the results of those students who voluntarily participated. The survey questionnaire contained information informing students of strict confidentiality.

\section{Instrument}

The investigator's conducting the study developed the survey that was used to gather the data needed to answer the research questions. The questions were based on ideas from the literature, suggestions from aviation faculty experts, and the investigator's own experiences. Anonymity was guaranteed and any data collected would remain confidential. The questionnaire contained 42 questions. The first five questions were used to gather descriptive statistics, calculating demographic characteristics of the sample. Twenty-five questions contained a sixpoint Likert-type scale with strongly agree and strongly disagree with anchoring points. A final question allowed participants to enter qualitative data on the use of simulation in air traffic control training.

The survey instrument used a closed-end design to facilitate coding through the use of numerical scores. The first section contained 6 questions requiring responses to demographically defined categories. A section containing 28 questions required a single response on a five-tiered ordinal scale from strongly agree $(+2)$ to strongly disagree $(-2)$, the anchoring points, to rate the desirability of the variable queried. Also, eight opened-ended questions were used to provide additional information on student perceptions of ATC simulation.

To preserve the anonymity of the respondents, we did not ask any questions that would allow for identification of participants, which is deemed essential in order to obtain accurate and candid responses.

Instrument Validity. Context validity for the test instrument was partially established through a peer review process. Two professionals in the aviation industry reviewed the data from the survey to ensure it would answer the research questions. 
Criterion validity was partially established through a field test of the survey questionnaire to determine if the instrument is predictive and reliable over time. Due to the constraints of the study, criterion validity was established based on a relatively small sampling of students from AT-CTI institutions with degrees in Air Traffic Management, Aeronautics, Aviation Management and some with minors in Air Traffic Control. To the degree that criterion validity was established by this procedure, it will be a positive indication that the instrument is predictive, but will provide a lower level of certainty that the instrument is reliable over time. As a result, reliability will be estimated rather than established.

\section{Results}

\section{Quantitative Findings}

Eighty-six participants completed the survey instrument, of which, 75 were undergraduates currently enrolled in ATC CTI programs, and 11 were alumni. For the 75 undergraduates ( 21 females), the average age was $21.53(S D=2.43)$, and for the 11 alumni ( 0 females) the average age was 32.91 ( $S D=14.44)$. Participants were recruited from University Aviation Association (UAA) member schools known to offer ATC simulation as part of their training curriculum. Participation was received from the following schools: Embry-Riddle Aeronautical University, the University of North Dakota, the Florida Institute of Technology, Hampton University, Minnesota State University-Mankato, and Florida International University. The results of the quantitative data are provided below and summarized in Figure 1.

\section{Effects of Stress}

Participants were presented with a series of four questions that related to their level of stress when completing simulator scenarios. This section sought to gain an understanding as to whether or not students and alumni felt the simulator training was too stressful or if it even caused them to consider switching majors. Both current undergraduate students $(M=-0.21, S D=0.61)$ and alumni $(M=-0.25$, $S D=0.67)$ tended to disagree that they found the simulator sessions too stressful or too overwhelming.

\section{Enhancing ATC Knowledge}

In the second section, participants were asked four questions that related to their interpretations on how the use of the ATC simulator affected their knowledge 
of ATC procedures. Participants were asked how the simulator enhanced classroom lectures and helped them understand the course learning outcomes. Undergraduates $(M=1.59, S D=0.42)$ and alumni $(M=1.57, S D=0.61)$ both strongly agreed that the use of the simulator greatly enhanced their overall learning experience.

\section{Future Expectations}

The third section asked participants to evaluate their perceptions on how their simulator training would affect their future training and careers. Four questions asked how their undergraduate training would relate to future performance at the FAA Academy and performance as an air traffic controller. There was strong agreement from undergraduates $(M=1.59, S D=0.42)$ and alumni $(M=1.39, S D=0.69)$ that the training they received would prepare them well for their future training requirements at the FAA Academy and as air traffic controllers.

\section{Effectiveness}

Lastly, participants were asked two questions to evaluate their perceptions of the efficacy of the instructors and the use of the simulator in their degree programs. There were some noticeable differences on the level of effectiveness between undergraduate students and alumni. Undergraduate students strongly agreed $(M=1.51, S D=0.51)$ while alumni mostly agreed $(M=0.80, S D=1.16)$ that the instruction they received and the use of the simulator enhanced the effectiveness of their program. Additional information on the disparity between these two groups will be presented in the qualitative analysis.

\section{Qualitative Findings}

While the quantitative data in the previous section provides us with a detailed snapshot of the data, our secondary goal was to more closely examine the qualitative comments provided by participants. We asked participants to provide information about the biggest strengths and weaknesses that they perceived in the ATC CTI programs, as well as any recommendations for improvement that came to mind. We examine each of these issues in turn.

In doing so, we employed the use of NVivo, which is a software program used to help organize, analyze and code responses in unstructured qualitative data (e.g. interviews, surveys, transcripts). Using NVivo, we were able to generate clouds of data, revealing the terms and items most commonly used by participants 
to describe their attitudes and perceptions about how well the ATC CTI program helped to prepare them for attending and successfully completing the FAA Academy training course. Figure 2 presents a visualization of the process used to complete the qualitative portion of the study.

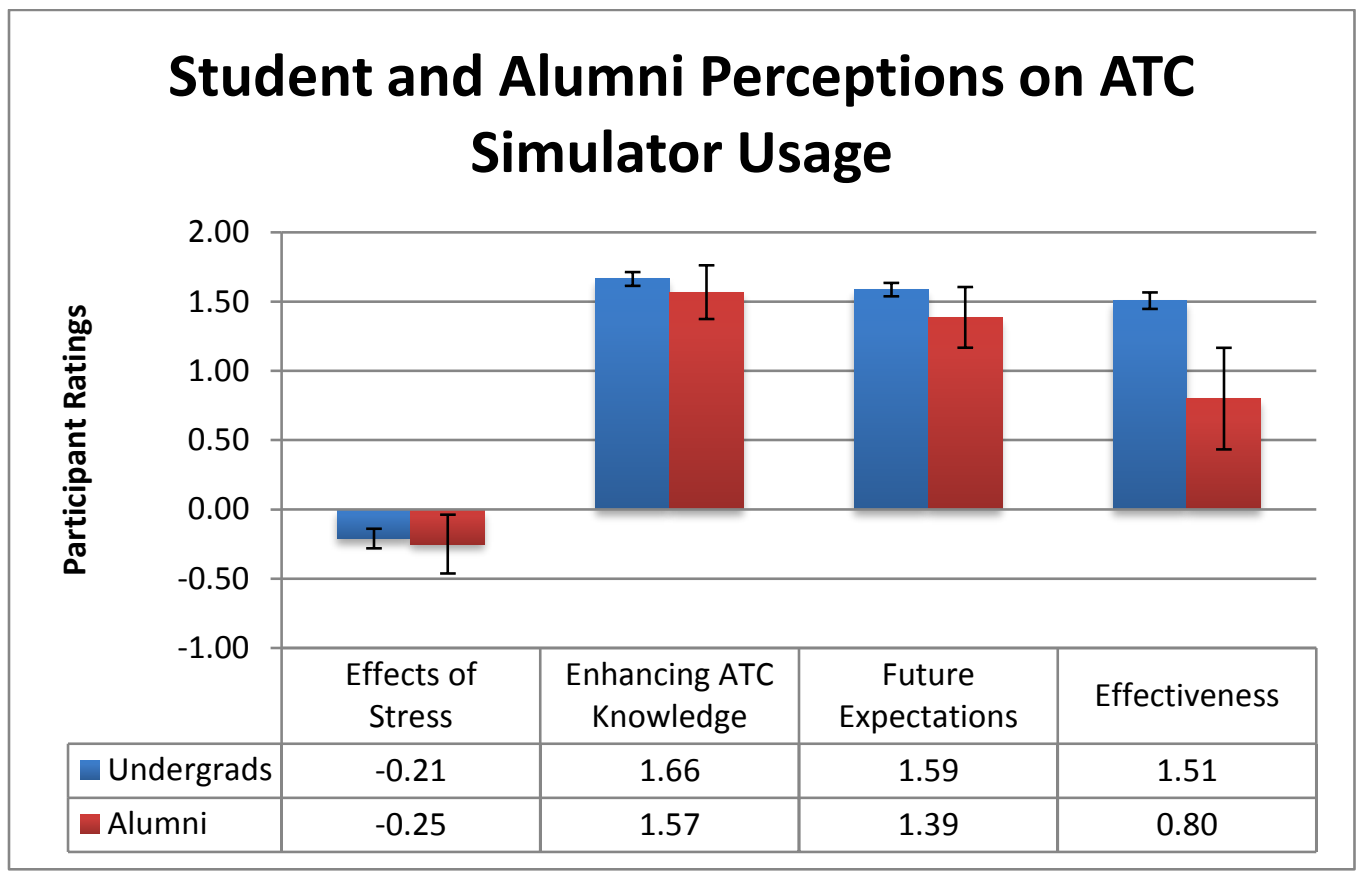

Figure 1. Comparing current student and alumni perceptions of the experience of using an ATC simulator for training in the Collegiate Training Initiative (CTI) program. Standard error bars included.

\section{Strengths of ATC CTI Program.}

Undergrads. In Figure 3, we can see that the undergraduate participants tended to focus their comments on the quality of instructors and professors who teach their courses. There were many positive comments about the professors, with several participants mentioning the expertise level of their instructors. Many of the participants mentioned their appreciation for having actual ex-controllers:

"We are lucky to have an actual controller teaching one of the required courses. He provides us with many real-life examples." 
"ATC 1 was taught by a real controller, so he gave real world example." "Professors with years of experience, the training equipment, and how close it can get to the academy."

"I think the instructors are one of the biggest strengths because they provide their real-world lessons to help us learn in the simulators."

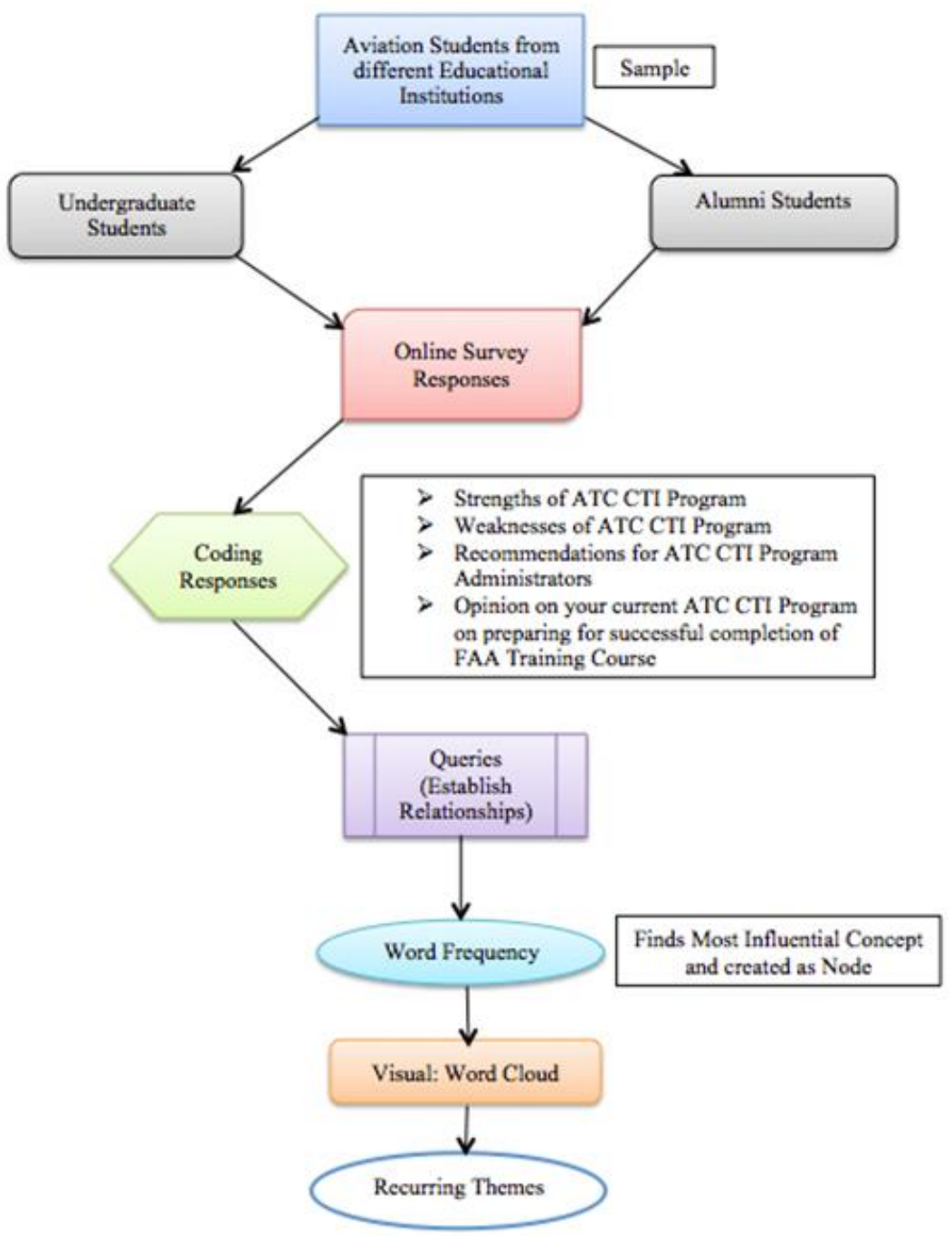

Figure 2. Data visualization for NVivo. 
In addition to the experience level of the instructors, undergraduate students also appeared to appreciate the different teaching styles. This mirrors what they find in the FAA Academy, where different instructors also have different teaching styles that students need to adapt to. Several participants made comments such as the following:

"The instructors, and the fact that although they each have their teaching styles, they each bring a unique set of knowledge, real world experience, and regulatory interpretations into the classroom, just like how trainers at an FAA facility have their own unique personalities and teaching styles."

"Diversity of professor's teaching styles."

"The difference in teaching styles really help the student prepare for what is to come in training."

Also, the instructors' teaching experience and styles, undergraduate students were, in general, pleased with the quality of the simulators and simulations used in classes. This generated many comments about those aspects of the courses:

"The equipment is state of the art."

"The ability to not only learn in a classroom setting but then also apply what we learn in a simulated scenario."

"The technology that we are able to use is probably our biggest strength."

"The full simulator, by far. It's the single best implement, in my opinion, to learn how to apply correct procedures aside from being plugged into a real tower."

"Having simulators available for usage both in the classroom as well as outside the learning environment. In addition, being able to program scenarios to practice specific aspects is also very beneficial." 


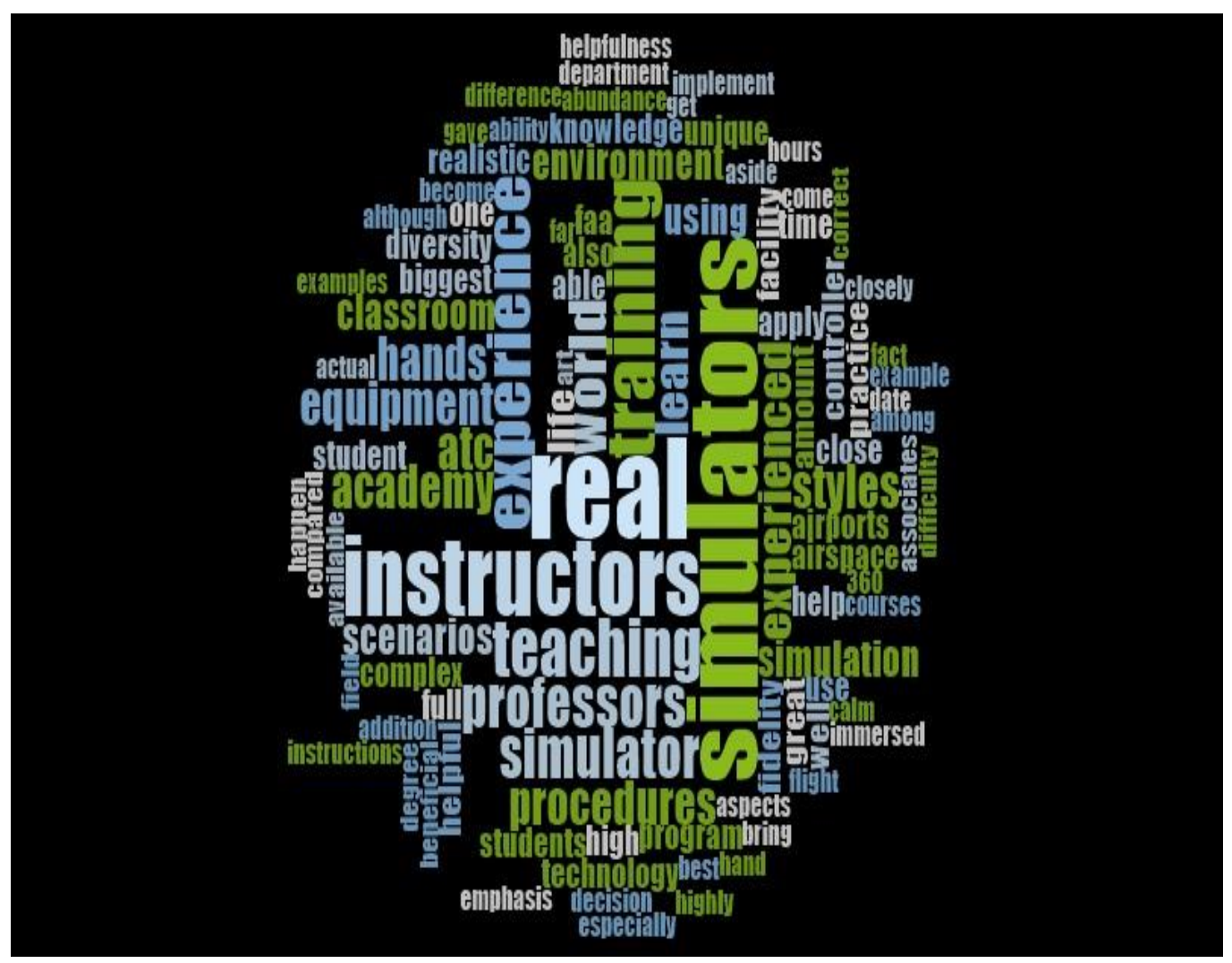

Figure 3. Strengths of ATC CTI Program - Undergraduates

Graduates. There were not as many graduate students as undergraduates, but the comments were similar to what the undergraduates valued. The quality and experience level of instructors was again highlighted:

"Having instructors who have been in the field and been there done that."

"Hands on learning with instructors who were former controllers."

Additionally, graduates also valued the use of simulators while they were in the ATC CTI courses:

"Multiple simulators. Quality instructors with real world experience."

"High quality simulation."

"Quickly delving into scenario work." 
One participant made it a point to highlight the similarity between the ATC CTI course they took and what they experience at the FAA Academy:

"Learning the key workings of all fields in ATC, from Enroute to Terminal, Non-Radar to TMU. Many other CTI programs only cover one aspect, primarily tower."

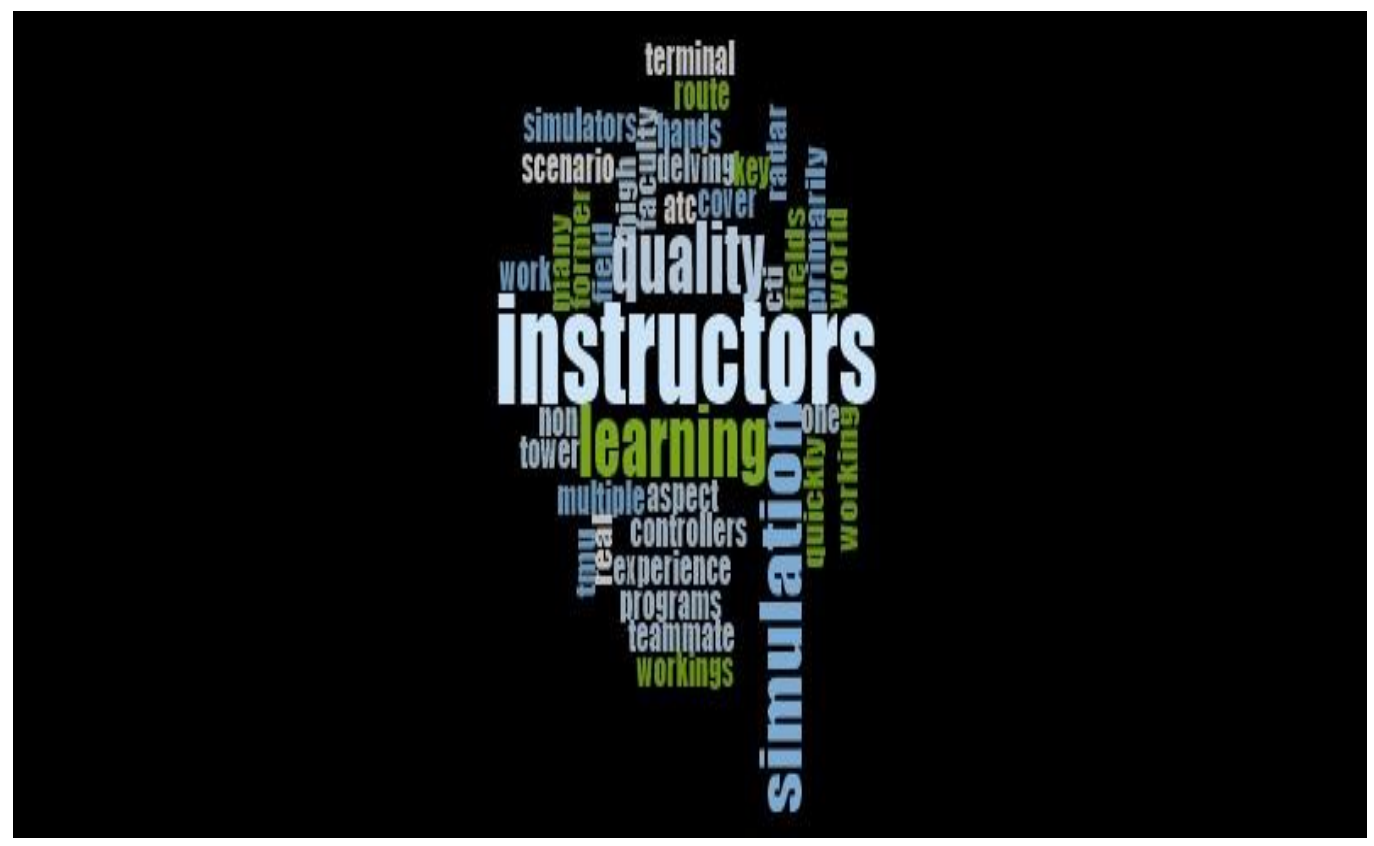

Figure 4. Strengths of ATC CTI Program - Graduates

\section{Weaknesses of ATC CTI Program.}

Undergrads. Not all of the comments about the ATC CTI programs were positive, and we analyzed the negative comments as well. Participants were specifically asked what they viewed the weaknesses of the programs to be. While the previous section revealed that students valued the simulator time they were exposed to, many of them regret not being able to do more simulator examples:

"...not enough time in the simulator, too many students in a class cuts down on the time to practice." 
"The relative inflexibility of the scenarios. It's not that the scenarios aren't good, it's that there aren't very many of them. I believe a large reason for this is the fact that new laminated strips have to be arranged for each scenario."

There were also quite a few complaints about the quality of the simulators. Many students shared the feeling that the simulators were outdated and/or not up to par compared to what they would experience at the FAA Academy:

"I think the software in the simulators is pretty outdated and could be updated."

"... outdated software not reflecting today's technology, ie. ERAM, STARS..."

"they need an update in terms of equipment."

"Outdated technology."

"At times the simulations are not accurate, sometimes instruction that could be given cannot because of computer limitations."

Interestingly, while many of the participants valued the diversity of the professors and instructors, some of them felt that this was also a weakness in their ATC CTI program:

"Contradicting information; once [sic] professor tells you one thing and another tells you the opposite."

"...standardization of information from one professor to the next."

"Each instructor has their own way of operating and they are adamant that their way is the only correct way."

In addition to the complaints about the facilities and instructors, some participants felt that the classes were too big and/or they were not getting enough time to process information:

“"big" classes - few scenarios - hard to really compare to the real world."

"I couldn't practice by myself, hard to find a partner." 
"Lack of clubs outside of the classroom."

"Need to break things down a little bit more."

"Only taking the ATC classes 2 days a week."

"Way too fast paced for non-flying students."

"The amount of time spent in the lab."

Lastly, many students seemed to feel that they were not being given enough information about different aspects of ATC and that it would be more beneficial to focus on various areas:

"only practicing as approach or departure."

"We, as an organization, are more focused on terminal procedures and do not teach oceanic specific procedures, and only have two enroute courses."

"Lack of enroute training."

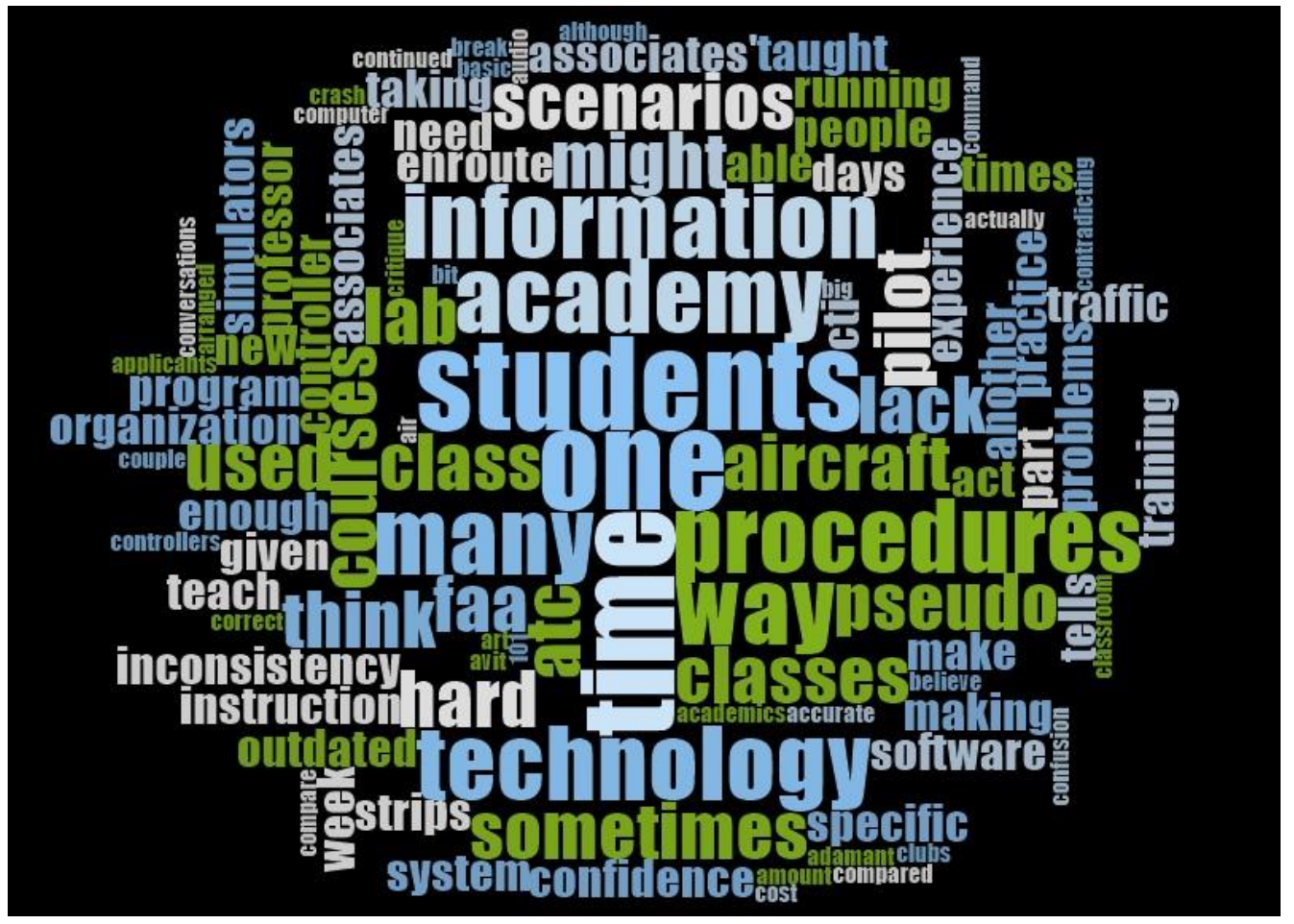

Figure 5. Weaknesses of ATC CTI Program - Undergraduates 
Graduates. Some of the comments from graduate students mirrored those from the undergraduates; however, overall it must be noted that the graduate students did not have as many negative comments as the undergraduates did. Some of their concerns were as follows:

"[Need to have] better simulators."

"Unfortunately when I graduated it was at the end of the shutdown and the start of the new hiring practices by the FAA. Therefore, if the degree program had more of a data/ research aspect I could have been better prepared for other career fields related to ATC."

"None of the scenario work related to what is currently being taught at the FAA Academy."

"Class time, should be longer."

"Not enough enroute training."

"Faculty frequently disagreed on how to do things. In-fighting sometimes made concepts difficult to remember."

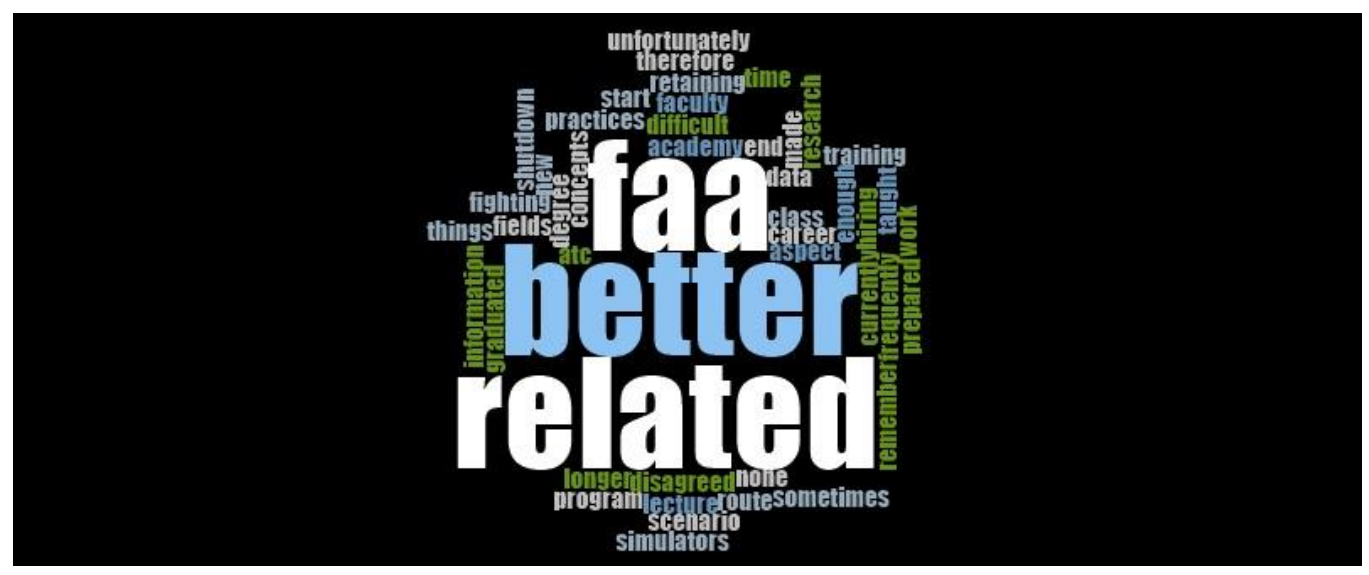

Figure 6. Weaknesses of ATC CTI Program - Graduates

Recommendations for ATC CTI Programs.

Undergraduates. While pointing out many of the perceived weaknesses in the ATC CTI programs, current undergraduate students also offered some 
suggestions for improvements. This followed several themes, as detailed below. The biggest issue seemed to be making the ATC CTI program more like the FAA Academy:

"More work in academy airspace."

"Make the technology mimic the ones used in real facilities and make the scenarios different every time."

"Also, change the non-radar map to match the map and procedures done at the academy. The procedures done at [name of school] differ from the academy and could cause graduates problems at the Academy."

A second theme involved making the scenarios more realistic and offer more scenario options, as well as upgrading the simulators:

"to start scenarios already running, it will be more realistic."

"upgrade the simulators."

"Better scenarios with more capabilities."

"The only recommendation I have is to update the software."

"Update the 360 control tower lab with current airlines and aircraft."

The third theme around standardization across instructors and labs:

"try to have more open labs."

"While I like the attitude that different standards for each instructor gets us ready for real facilities' differing standards, I'd really like to know if that's intentional or not."

"standardize the lessons taught."

Lastly, students commented frequently on doing training in other areas that they did not get enough time in:

"Focus more on enroute training."

"Work with center controlling a little more." 
"Add an oceanic course, and update the route structure for the scenarios to include more SID/STAR procedures, and RNAV/GNSS routes."

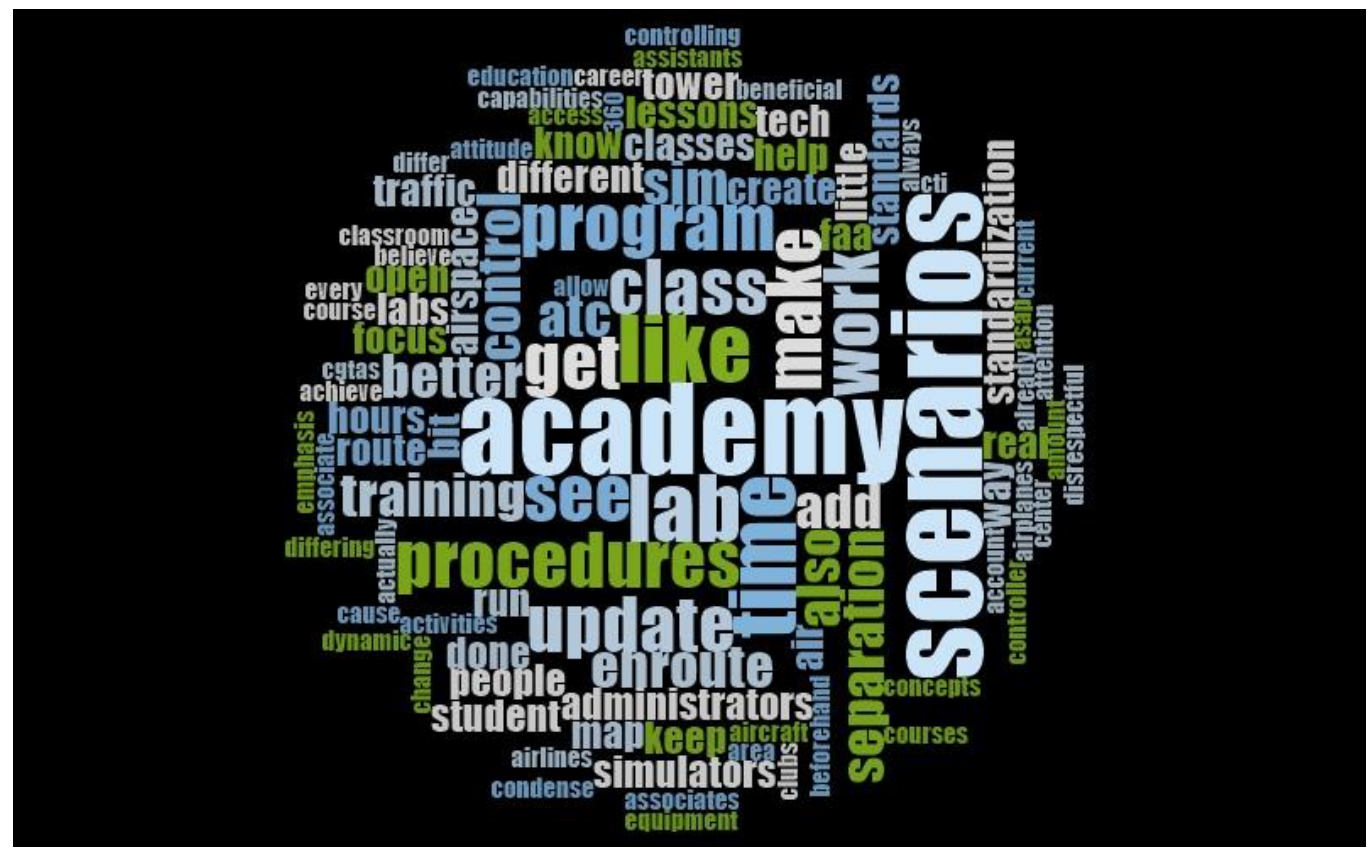

Figure 7. Recommendations for ATC CTI Program Administrators Undergraduates

Graduates. There were not very many recommendations made by the graduates, but of the ones we received, they tended to again mirror those of the undergraduates. They commented on the alignment (or non-alignment) between the ATC CTI program and the FAA Academy, as well as made suggestions related to instruction and simulations:

"Switch to Academy Airport in the tower simulators; it will only better prepare your students for VFR pattern work and situations they will see at the Academy. Also, Enroute at the Academy is heavily focused on ERAM and using all equipment the D-Side would have in the field. The D-Side's responsibilities are to recognize conflicts and solve them on their own."

"Get the enroute keyboards and run a class with only center operations." 
"Standardize procedures and phraseology. Drastically different procedures in different classes are ridiculous."

"Minimize talk and expand simulation."

"More realistic simulation."

"More streamlined towards academy procedures."

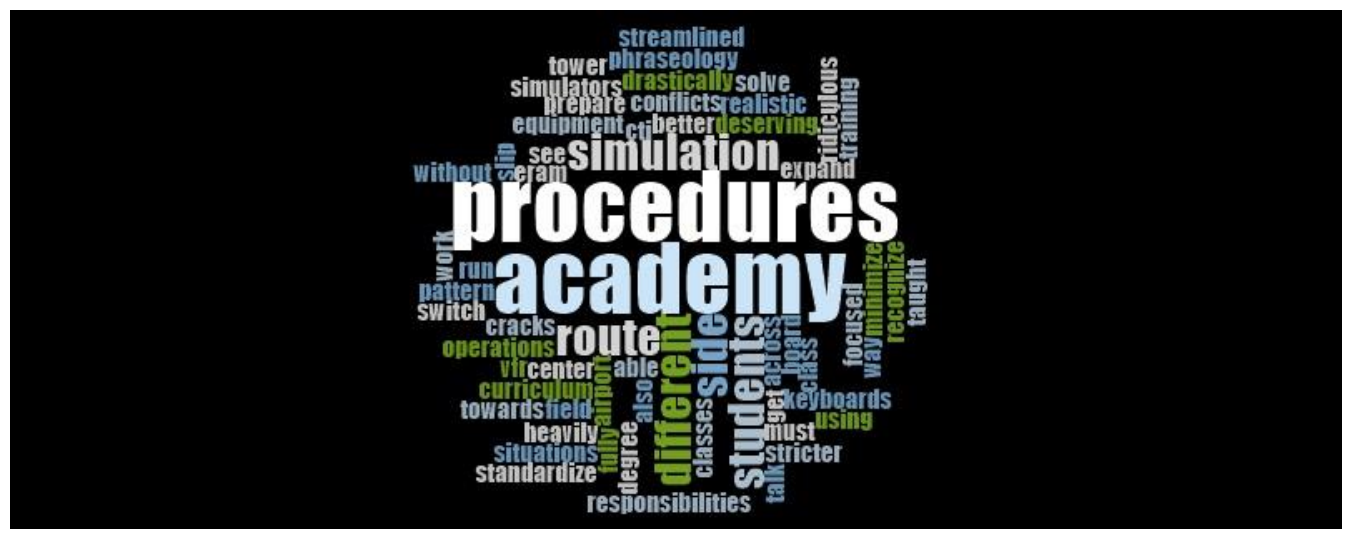

Figure 8. Recommendations for ATC CTI Program Administrators - Graduates

\section{Limitations}

A limitation of the study is the relatively small size of the sample, 86 participants, when compared to the large number of students in different university and professional training settings that use Air Traffic Control simulation for training. As a result, the data generated by this study was limited to the perceptions of undergraduate aviation students and learning environments at a few of the institutions in the AT-CTI program, with the findings subject to future modification from studies based on larger samplings.

The study was further limited by the potential for selection bias and researcher bias. Some degree of researcher bias can potentially be present in the selection of variables and the development of the terminology used in the survey questionnaires. Researcher bias may also be present in the selection of the general organizational data that form the literature review and the determination of the relevance of previous investigational methods and findings in the subject area.

While this study collected data on the perceptions undergraduate students have with specific air traffic control simulation use, it did not address essential 
characteristics of technology integration such as, the suitability of the technology for attaining objectives, levels of interface, availabilities of assets and backing for students and faculty.

\section{Conclusions}

The investigators found that the degree of faculty support during air traffic control simulation classes, learning as well as the degree of stress experienced by the student was statistically significant variables that influenced the results of the study. This might be the result of the faculty member's experience using simulation and knowing how far to let a student go in a scenario before interceding.

The investigators also found that there were significant differences in the perceptions of students regarding air traffic control simulation based on the demographic factors investigated in the study, and with students who had prior experience with air traffic control simulators or prior experience with simulation in another training environment. This may be because some students were more comfortable with technology and were able to capitalize on the learning experience and not worry about the technical aspects of the simulator.

\section{Recommendations}

While this initial study collected data on the perceptions of undergraduate students with which Air Traffic Control Simulators were being used, it did not address important aspects of simulation integration such as, the appropriateness of the simulation for achieving instructional goals, levels of interaction, availability of resources and support for students and faculty.

1. The investigators recommend to include student, faculty and technologists on future simulator acquisitions. The cost and benefit aspect to the student should be considered at both institutions. Based on the experience of faculty and previous simulator purchases, the future purchase should categorize the requirements at both schools and ensure they are in line with Federal Aviation Administration (FAA) requirements. These requirements should be reviewed regarding the impact on cost, design features, and student performance based on well-defined objectives. This may assist in the negative responses about simulator costs.

2. It is recommended that future research includes students from a greater number of universities in the AT-CTI program. Doing so would enable one to generalize the findings more broadly. Simulation learning appears to be a part of the teaching methodologies of the future. 
The findings imply that researchers and administrators need to view the utilization of simulation as an integral part of teaching methodologies. Students seem to prefer simulation when integrated with traditional teaching methods. Although not entirely traditional, Air Traffic Control students may be better served with "a multipurpose training device that will allow students to complete knowledge acquisition lessons, part-task training exercises, cognitive lessons, and simulation practice should be used" (Fisher \& Kulick, 1998, p. 293). There are more benefits to the use of Air Traffic Control simulators, at least from the students' perspective. As universities move forward with new technology and the use of simulation, administrators need to consider student perceptions. 


\section{References}

Allermand, G. \& Rosenkvist, C. (2011). Training philosophy, guiding training technology. ICAO Training Report, 1(1), 41-44. Retrieved from http://www.icao.int/publications/journalsreports/2011/icao_training_report _vol1_no1.pdf

Baron, R. (2014). Barriers to effective communication: Implications for the cockpit. Retrieved from http://airlinesafety.com/editorials/BarriersToCommunication.htm

Blanken, M. J. S. (2002). Chapter 13: Theory and Research - Training for Future ATM. In H. Eissfeldt, M. C. Heil, \& D. Broach (Eds.), Staffing the ATM system: The selection of air traffic controllers (pp. 155-167). Burlington, VT: Ashgate.

Federal Aviation Administration (FAA). (2006). FAA air traffic control behavioral standards/academic standards. Oklahoma City, OK: Federal Aviation Administration Academy. Retrieved from http://www.faa.gov/about/office_org/headquarters_offices/ato/service_unit s/acquisition/aja51/cti/media/Behavioral\%200bjectives.doc

Federal Aviation Administration (FAA). (2010a). AT-CTI Participation Package. Oklahoma City, OK: Federal Aviation Administration, Air Traffic Controller Training and Development Group (AJA-51).

Federal Aviation Administration (FAA). (2010b). Fact sheet-Next generation air transportation system. Retrieved from https://www.faa.gov/news/fact_sheets/news_story.cfm?newsId=10856

Federal Aviation Administration (FAA). (2013). A plan for the future: 10-year strategy for the air traffic controller workforce 2013-2022. Retrieved from http://www.faa.gov/air_traffic/publications/controller_staffing/media/CW P_2013.pdf

Federal Aviation Administration. (2015). Florida test bed. Retrieved from http://www.faa.gov/about/office_org/headquarters_offices/ang/offices/tc/a bout/campus/faa_host/labs/csi_team/ftb/

Federal Aviation Administration (FAA). (2016a). The economic impact of civil aviation on the U.S. economy. https://www.faa.gov/air_traffic/publications/media/2016-economicimpact-report_FINAL.pdf 
Federal Aviation Administration (FAA). (2016b). A plan for the future: 10-year strategy for the air traffic controller workforce, 2016-2025. Retrieved from http://www.faa.gov/air_traffic/publications/controller_staffing/media/cwp _2016.pdf

Federal Aviation Administration (FAA). (2016c). Aviation careers. Retrieved from http://www.faa.gov/jobs/career_fields/aviation_careers/

Federal Aviation Administration (FAA). (2016d). NextGen programs. Retrieved from http://www.faa.gov/nextgen/programs/

Fisher, S.G., \& Kulick, I. (1998). Air traffic controller training: A new model. In M.W. Smolensky \& E.S. Stein (Eds.), Human factors in air traffic control (pp. 273-293). San Diego, CA: Academic Press.

Gall, M. D., Gall, J. P., \& Borg, W. R. (2006). Educational research: An introduction (8th ed.). Boston: Pearson Education.

Hopkin, V.D. (1995). Human factors in air traffic control. London: Taylor \& Francis.

Means, B., Mumaw, R., Roth, C., Schlager, M., McWilliams, E., Gagne, E., et al. (1988). ATC training analysis study: Design of the next-generation ATC training system. Alexandria, VA: HumHRO International.

Mertler, C.A., \& Vannatta, R.A. (2002). Advanced and multivariate statistical methods: Practical application and interpretation (2nd ed.). Los Angeles: Pyrczak.

Northern NEF, Inc. (1988). Flight plan for the future: Training controllers for the National Air Traffic Control System (OPM Subcontract Agreement SubOPM88-04). Colorado Springs, CO: Author.

Patty, A. (2016, October 2). Fatal consequences of miscommunication between pilots and air traffic controllers. The Sydney Morning Herald. Retrieved from http://www.smh.com.au/business/workplace-relations/the-fatalconsequences-of-miscommunication-between-pilots-and-air-trafficcontrollers-20160927-grq1d9.html

Ruiz, J. R., \& Ruiz, L. E. (2003). Collegiate aviation and FAA air traffic control. Journal of Aviation/Aerospace Education and Research. 12, 3, 43-51. 
Schneider, W. (1990). Training high performance skills: Fallacies and guidelines. In M. Venturino (Ed.), Selected reading in human factors (pp. 297-311). Santa Monica, CA: Human Factors Society.

Treiber, K. (1994, September). Sweaty palms!: Virtual reality applied to training. Paper presented at the annual meeting of the American Vocational Association Convention, Dallas, TX. (ERIC Document Reproduction Service No. ED377383)

Van Merrienboer, J. J. G. (1997). Training complex skills: A four-component instructional design model for technical training. Englewood Cliffs, NJ: Educational Technology.

Wall, M. (2014). Flight 370 mystery: How can a jetliner drop off the radar? Retrieved from http://www.livescience.com/44012-malaysian-airlinesmystery-radar-tracking.html

Work, C. (2007). Air traffic-collegiate training initiative. Oklahoma City, OK: Federal Aviation Administration, Air Traffic Controller Training and Development Division. 